Thorax (1963), 18, 371

\title{
Radiation damage to thoracic tissues
}

\author{
A. G. W. WH I T F IELD, ${ }^{1}$ W. H. BOND, AND P. B. KUNKLER ${ }^{2}$ \\ From the Departments of Medicine and Radiotherapy, United Birmingham Hospitals, \\ University of Birmingham
}

\begin{abstract}
Radiotherapy to the thorax in conventional dosage appears to be capable of causing damage to any of the tissues in the thoracic wall or within the thoracic cavity. Since the earliest days of $x$-ray treatment radiation changes in the skin have been such an everyday problem that they scarcely warrant discussion here except to note that with the advent of new radiotherapeutic techniques they are becoming less frequent and less severe.
\end{abstract}

\section{THE THORACIC WALL, SHOULDER GIRDLE, AND BREASTS}

Radiation damage to the bony structure of the thoracic cage is relatively uncommon. Rib fractures are its most frequent manifestation and their symptom is pain. Their presence in one or several ribs is confirmed by careful scrutiny of the chest radiograph (Fig. 1). They must, of course, be differentiated from pathological fractures resulting from metastases, but if they occur after radiotherapy to the thorax the great probability is that they are attributable to it. Expansion of the bone is never seen, the fractures usually occur in the anterior axillary line, and surprising though it is they unite well and pain soon abates (Fig. 2). They usually follow radiotherapy for breast cancer but may be a sequel to $x$-ray treatment for other thoracic disorders. Some concomitant radiation damage to the lung is commonly evident. Age does not appear to be a factor in their causation as we have seen them in early adult life. They have been previously described by Fike (1932), Freid and Goldberg (1940), Eggs (1941), Leach, Farrow, Foote, and Wawro (1942), Blumenfeld and Thomas (1945), Braun and Frik (1954), Kolář and Vrabec (1957), and Baudisch (1960). Koláŕ and Vrabec (1957) and Baudisch (1960) have also reported radiation fractures of the clavicle after postmastectomy radiotherapy for breast cancer, and Borgström and Gynning (1957) described osteoporotic vertebral collapse after intense rotation

1 Paper given at the Tenth International Congress of Radiology in

Montreal, 1962 Present address: Radiotherapy Department, United Cardiff Hospitals roentgen therapy for cancer of the oesophagus, but we have not encountered these lesions.

After mastectomy and radiotherapy for breast cancer the shoulder not uncommonly becomes fixed or relatively so, and in such cases osteoporotic changes may be seen in the humerus and scapula (Fig. 3). To what extent such processes stem directly from radiation and how much they are attributable to disuse one cannot be certain but the latter is probably an important influence.

Other types of bony lesion are occasionally seen. Two examples are shown in Figures 4 and $5 \mathrm{a}$. Figure 4 shows the shoulder of an old lady who, after radiotherapy for breast cancer, developed shoulder pain attributable to necrosis of the head of the humerus. Figure 5a is from a woman who at the age of 10 was given radiotherapy for what at thoracotomy was thought to be an inoperable malignant lung tumour. No biopsy was taken. Thereafter the scapula failed to grow to its normal size and the breast was also affected (Fig. 5b). When at the age of 30 she gave birth to a child there was no lactatory response on the damaged side. Mammary hypoplasia following radiotherapy in childhood has been reported previously (Rübe, 1954 ; Koláŕ, Vrabec, and Bek, 1957 ; Gros and Keiling, 1958).

\section{THE LUNGS}

The lungs are the most vulnerable of the tissues within the thorax, and radiation damage is still relatively common after $x$-ray treatment for breast cancer, though it occurs much less frequently than in the early days of radiotherapy. This is particularly so after wide-field irradiation for malignant lymphomas or lung secondaries. Six cases, two of them fatal, have recently been reported after radioactive iodine therapy for carcinoma of the thyroid with pulmonary metastases (Rall, Alpers, Lewallen, Sonenberg, Berman, and Rawson, 1957) but we have not encountered radiation lung damage arising in this way. In a series of 49 cases which we have studied, 25 followed routine postmastectomy radiotherapy for breast cancer, 11 


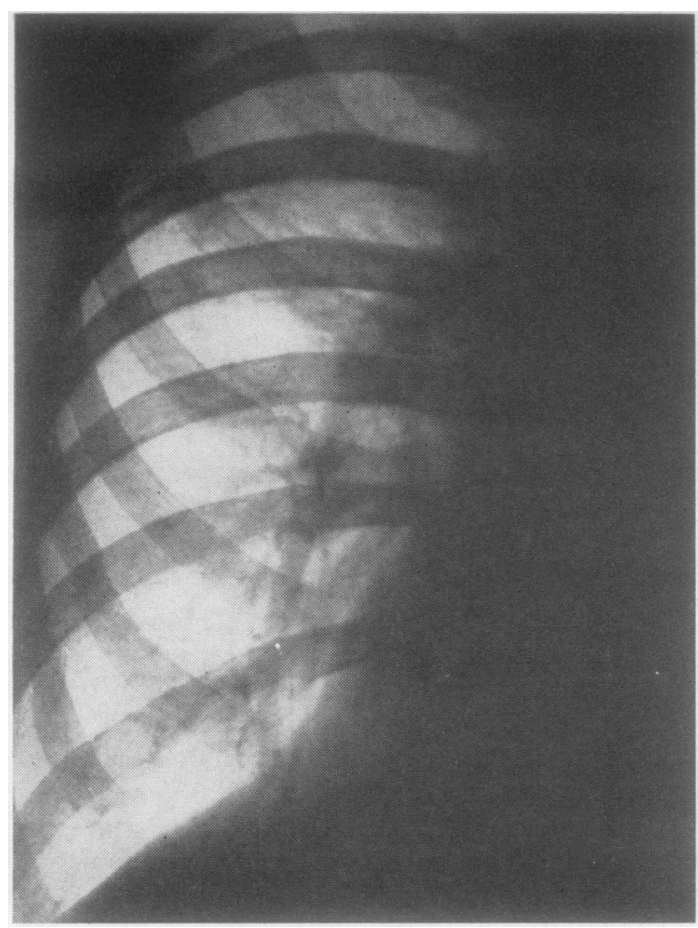

FIG. 1. Female, aged 40. Fractured sixth and seventh ribs after post-mastectomy radiotherapy for breast cancer. Some radiation damage to the right lung is evident.

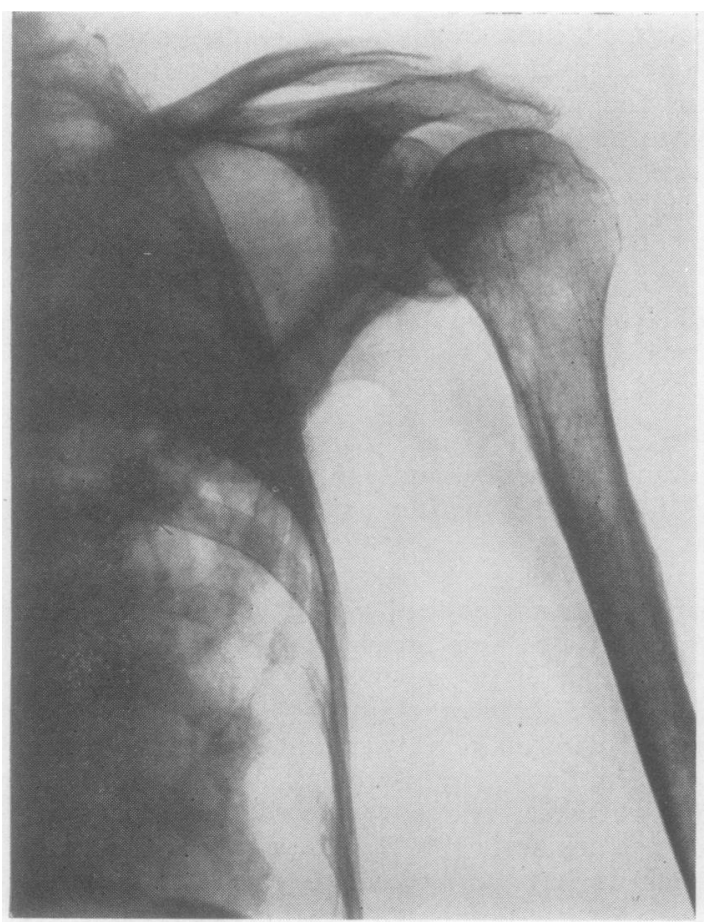

FIG. 3. Female, aged 49. Fixation of left shoulder with osteoporosis of humerus and scapula after mastectomy and radiotherapy for breast cancer. Severe radiation damage to the left lung is also shown.

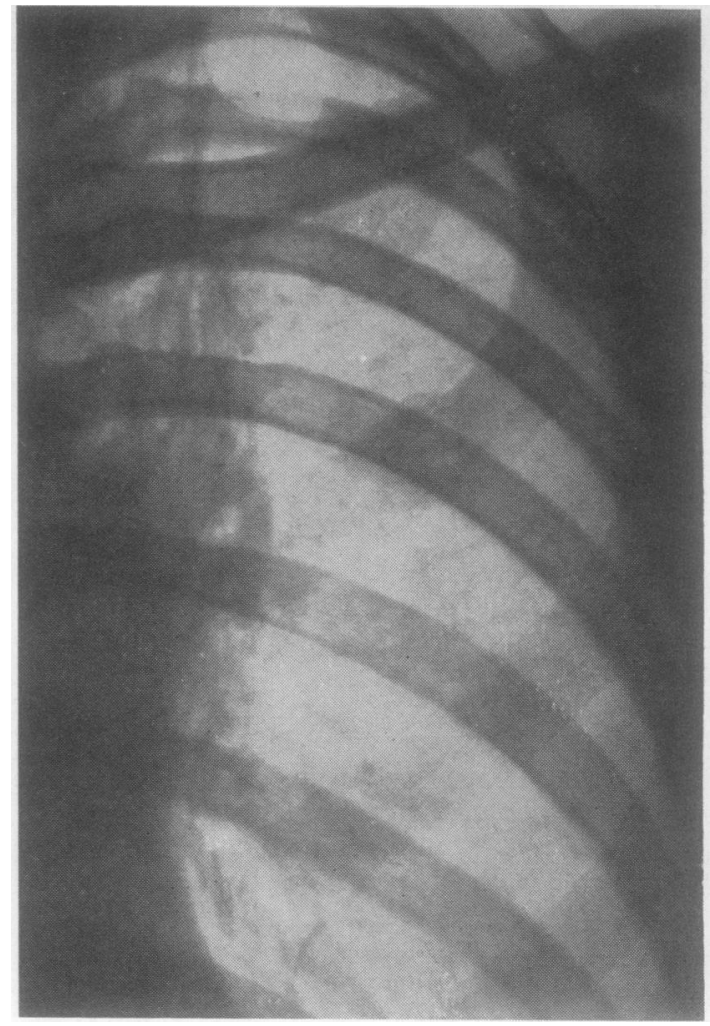

FIG. 2. Female, aged 27. Soundly united fracture of left second rib six months after radiotherapy through mediastinal fields for Hodgkin's disease involving mediastinal lymph nodes. Radiation fibrosis of the lung is also present.

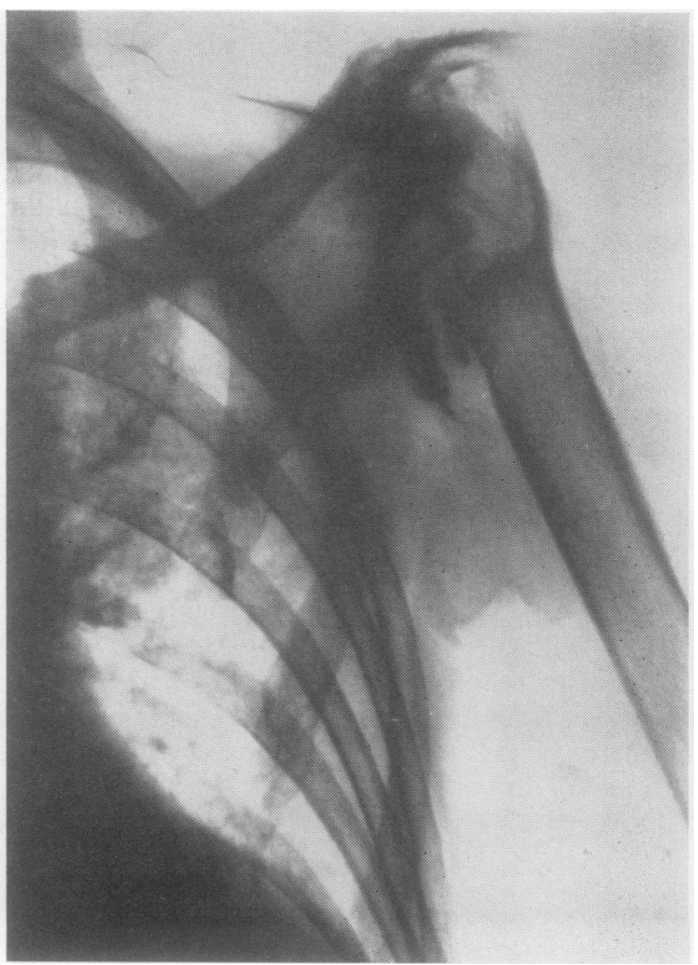

FIG. 4. Female, aged 84. Necrosis of head of humerus after radiotherapy for breast cancer. Radiation fibrosis of the lung is also evident. 

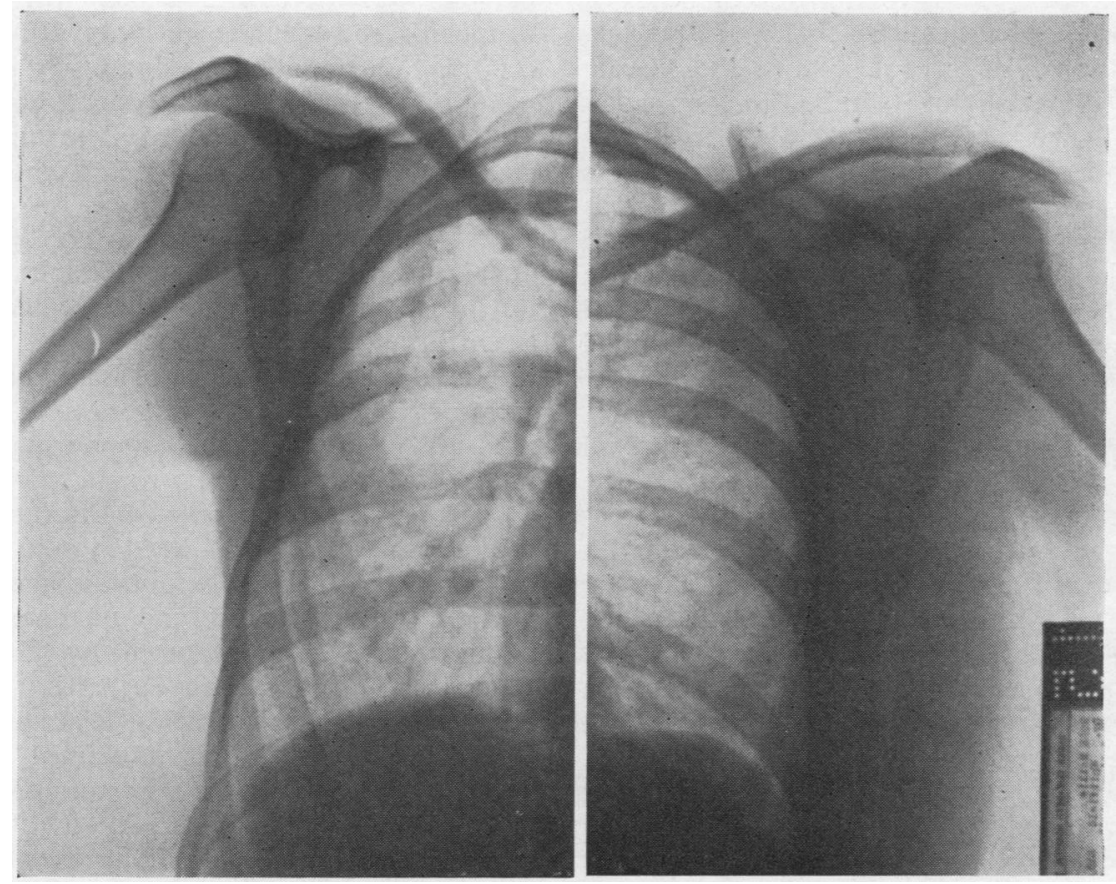

FIG. 5a

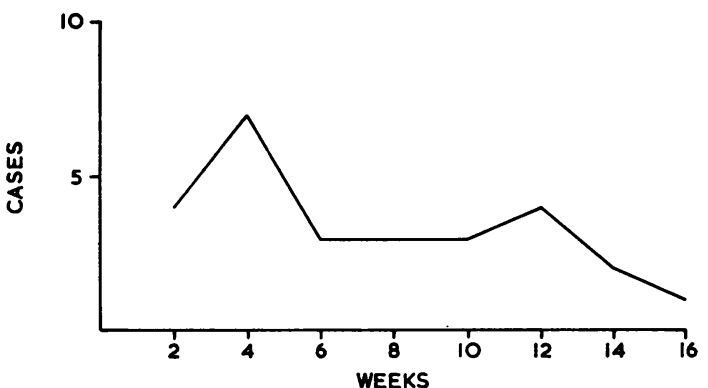

FIG. 6

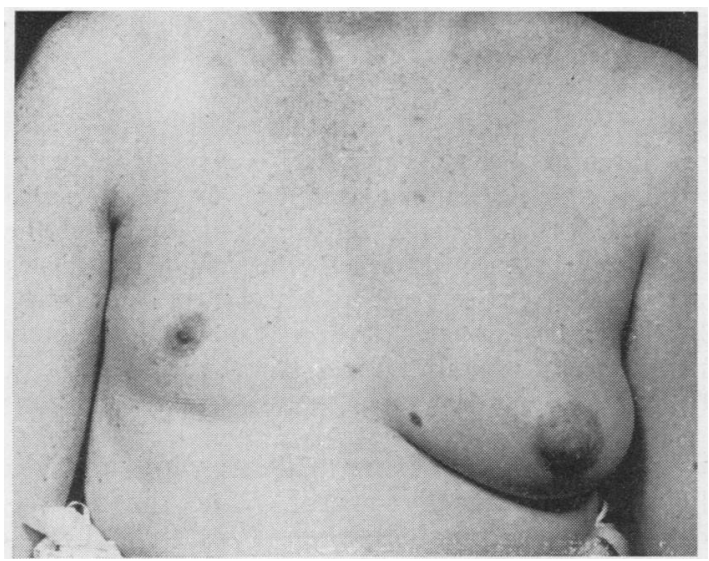

FIG. 5b

FIG. 5a. Female. Failure of right scapula to grow to its normal size following radiotherapy in childhood for a malignant lung tumour. Radiation fibrosis of lung also present.

FIG. 5b. Same patient as in Fig. 5a, showing mammary hypoplasia on treated side.

FIG. 6. Interval between conclusion of radiotherapy and onset of symptoms of radiation pneumonia.

FIG. 7. Symptoms in patients with radiation lung damage.

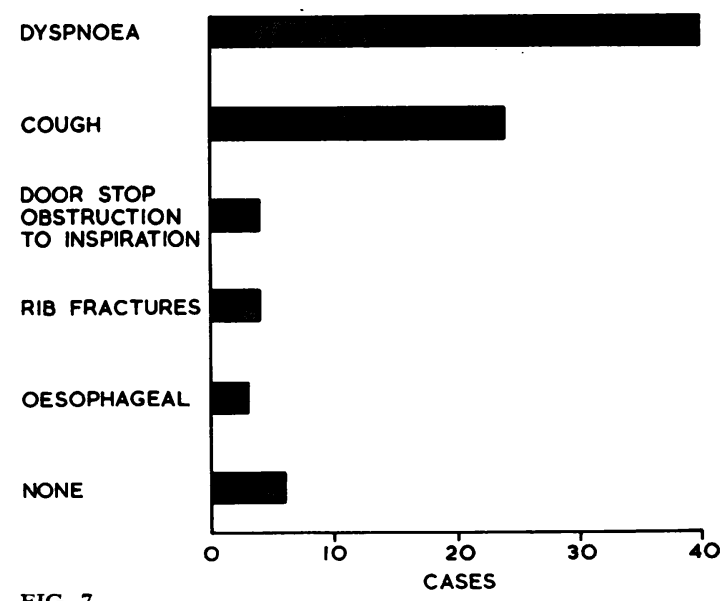

FIG. 7 
occurred after chest baths for lung secondaries or malignant lymphomas, two followed therapy directed to the whole of one side of the thorax, six occurred after treatment limited to the mediastinum, and the remaining five followed treatment through limited fields for carcinoma of the bronchus or oesophagus. Where radiotherapy was unilateral, the lung damage was limited to the treated side in all but one case, whereas when both lungs had been treated all save one suffered bilateral damage. It was usually strikingly limited to the area irradiated.

SYMPTOMS AND PHYSICAL SIGNS The interval between the conclusion of $x$-ray treatment and the development of symptoms attributable to radiation pneumonia varied from 1 to 16 weeks with a peak incidence at one month (Fig. 6). Six patients had no symptoms (Fig. 7) and their lung damage was slight and was only revealed by routine follow-up radiography of the chest. In the remainder dyspnoea was the dominant symptom. At first only evident on exercise, it increased rapidly and in severe cases became obvious at rest. In those who survived it gradually diminished over a period of weeks but only exceptionally was a normal exercise tolerance ever restored. A 'door stop' obstruction to full inspiration is evident in severe cases and was a striking feature of four of the patients studied. Half the patients had a dry irritating cough aggravated by exercise or deep breathing. In some this symptom was only present in the pneumonia stage, but in many it persisted in lesser degree indefinitely. Sputum was unusual both during the pneumonia stage and when fibrosis had supervened, no doubt because the upper lobes are most commonly affected.

Fractured ribs were noted in four patients. They gave rise to severe pain, but in the absence of such lesions radiation pneumonitis is strikingly painless. Oesophageal symptoms were sometimes present but not commonly at the same time as the dyspnoea and cough of acute radiation pneumonia. The dysphagia of radiation oesophagitis has usually subsided before the symptoms of pneumonia develop, and when sometimes the intrathoracic fibrosis produces an hiatus hernia, the lung damage has progressed to the fibrotic stage. Pyrexia was unusual, only occurring in two of the group studied.

Conventional physical examination of the chest was usually negative in the pneumonia stage but in severe unilateral cases subsequent fibrosis gave rise to tracheal and mediastinal shift and to some alteration in the breath sounds and dullness to percussion over the affected lung. Some of our patients were left with a tendency to recurrent bronchitis and pleurisy but only one was bronchiectatic. During the pneumonia stage the sedimentation rate was usually considerably raised but the only haematological abnormality we have found was a slight polymorphonuclear leucocytosis in three of our most severe cases.

RESPIRATORY FUNCTION TESTS Respiratory function tests were only occasionally performed but showed a uniform pattern of abnormality. There was a diminution in all divisions of lung volume, but the ratio of the various divisions to total capacity was not significantly altered from normal. The maximum breathing capacity was likewise markedly reduced. The arterial oxygen saturation was normal at rest but severe cases showed desaturation on exercise, while the carbon dioxide content was normal or low at rest and on exercise. Similar findings have been reported by Leach (1943b), Baldwin, Cournand, and Richards (1949), Stone, Schwartz, and Green (1956), Rodman, Karr, and Close (1960), and Cooper, Guerrant, Harden, and Teates (1961). We have not examined the carbon monoxide diffusing capacity in any of our patients but such abnormal physiology as we and others have found indicates the presence of alveolocapillary block, and the histopathological features immediately confirm that such must be the dominant functional defect.

PROGNOSIS Seven of our 49 patients, all with severe bilateral damage, died as a result of alveolocapillary block. The remaining 42 survived or died from other causes. In only two of these did the lungs revert to normal, the remainder showing varying degrees of residual fibrosis and disability. In fatal cases deterioration can be extremely rapid; three of our patients died within days of the onset of serious dyspnoea.

PATHOLOGY Four of our patients with radiation lung damage came to necropsy and the findings have been reported elsewhere (Whitfield, Lannigan, and Bond, 1954 ; Whitfield, Bond, and Arnott, 1956 ; Whitfield and Bond, 1959). In the gross the lungs are firm, rubbery, and airless, and on the surface depressed scars may be evident. Histologically, the striking feature is loss of alveolar space. This is due first to thickening of the alveolar walls which show lymphocytic infiltration, fibrosis, and thickening and fragmentation of the elastic tissue ; secondly to swelling of the alveolar lining cells; thirdly to the presence within the alveoli and alveolar ducts of hyaline membrane, organizing exudate, desquamated cells, and macrophages, 
some of which contain lipoid material; and fourthly to the collapse of some alveoli. An increase in the fibrous tissue around bronchi and large vessels is also seen.

RADIOLOGY The development of dyspnoea and dry cough a month or so after radiotherapy to the thorax strongly suggests the presence of radiation lung damage: the tendency to spontaneous improvement together with the respiratory function test pattern of alveolo-capillary block provide good supporting evidence. The usual diagnostic difficulty is that of differentiating radiation pneumonia from neoplastic involvement of the lungs (Whitfield et al., 1956), and here the chest radiograph is of paramount importance: indeed the diagnosis cannot be made with certainty without it. In the pneumonia stage the appearances after irradiation for breast cancer are those of upper lobe consolidation though the abnormality is not anatomically lobar in distribution, while after wide-field irradiation of the thorax the radiographic pattern is that of oedema (Fig. 8). In the course of a few weeks the lung shadowing begins to clear, and evidence of fibrosis with pleural and pericardial tenting (Fig. 9) and, in unilateral cases, mediastinal shift (Fig. 10) becomes apparent. Radiological improvement continues for some years but complete radiographic resolution is exceptional and only occurred in two of our patients. The lung damage as shown on the chest radiograph is usually strictly limited to the area irradiated, and this, together with the tendency to spontaneous clinical and radiographic improvement, strongly favours a diagnosis of radiation damage as opposed to neoplastic involvement.

TREATMENT When there is such a striking tendency to spontaneous improvement it is difficult to assess the value of therapy. Steroids have been widely employed and are probably of limited use (Whitfield et al., 1956; Rubin, Andrews, Paton, and Flick, 1958; Douglas, 1959; Lougheed and Maguire, 1960 ; Rodman et al., 1960), though the occasional slight relapse when steroids are prematurely withdrawn certainly suggests that they are of some benefit (Cosgriff and Kligerman, 1951 ; Bluestein and Roemer, 1953 ; Whitfield, Bond, and Arnott, 1954). Other writers have reported no improvement (Stone et al., 1956;

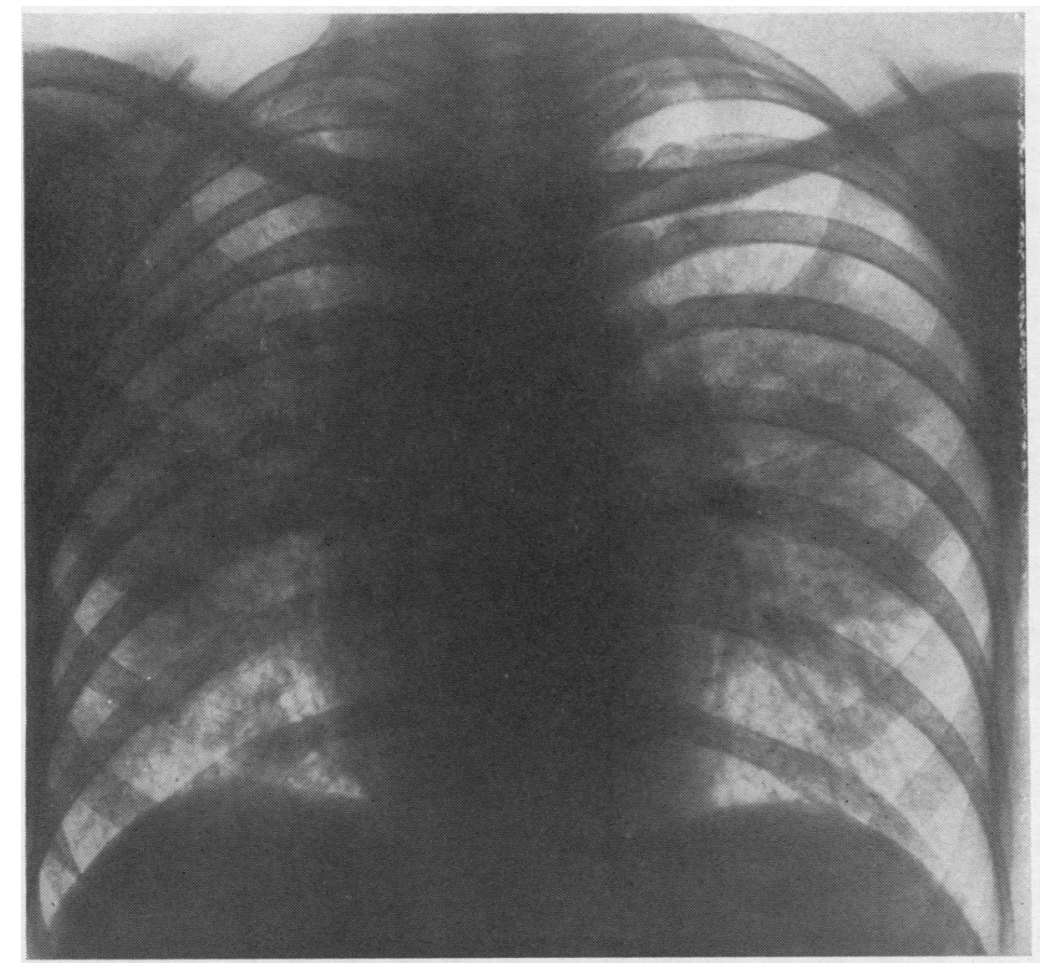

FIG. 8. Acute radiation pneumonia after chest baths for mediastinal Hodgkin's disease. Appearances are those of pulmonary oedema. 


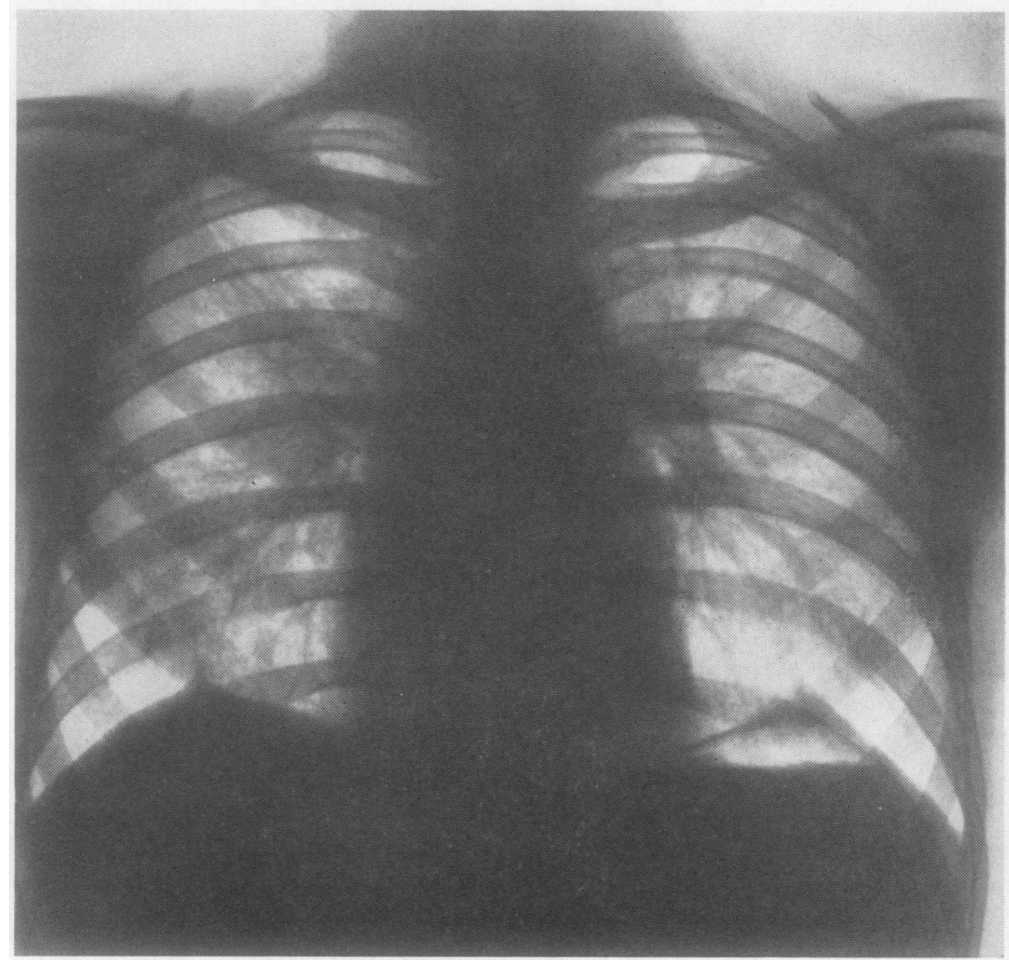

FIG. 9. Radiation pneumonitis showing evidence of progression to fibrosis.

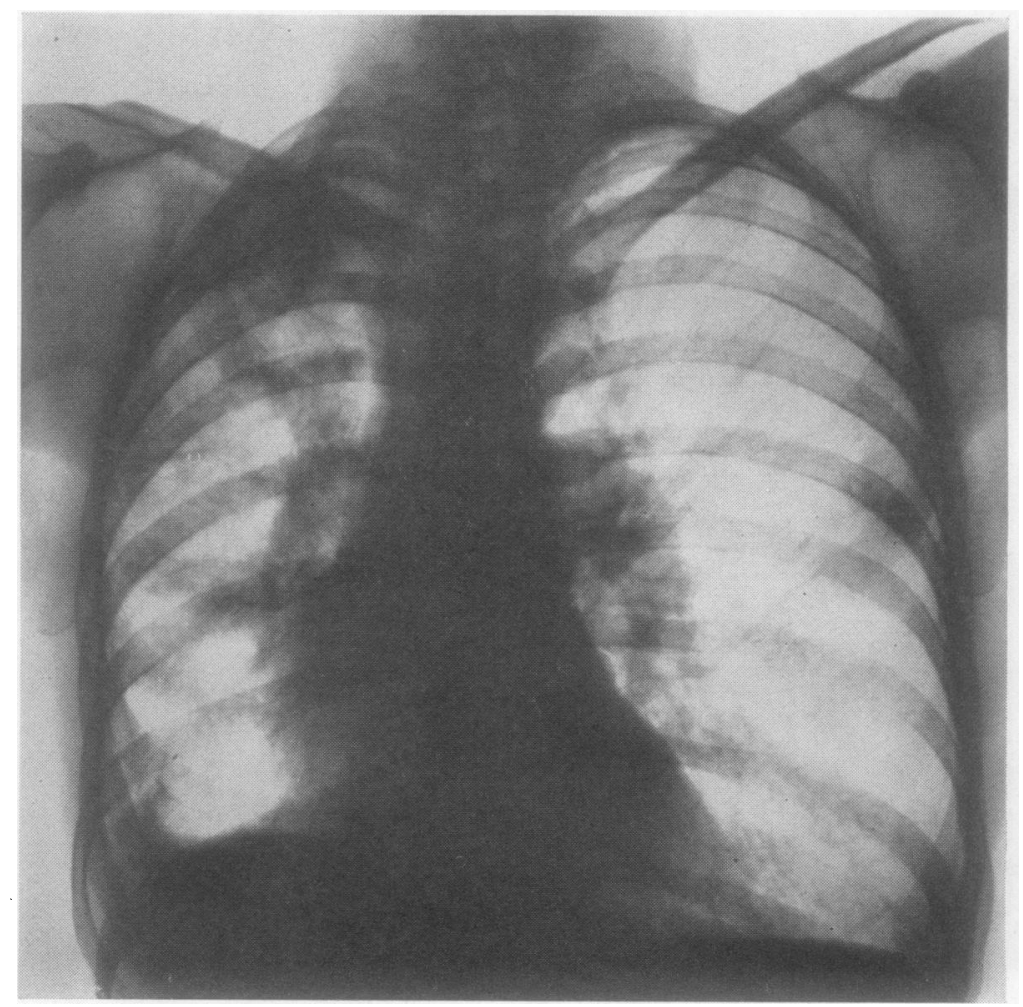

FIG. 10. Unilateral fibrosis after irradiation for breast cancer. 
Lichtenstein, 1960) or no more than would have been expected to occur spontaneously following their use (Chu, Nickson, and Uzel, 1956).

Nine of our 49 patients were given steroids, and of these five showed marked improvement though all were left with some residual fibrosis. Three died from radiation lung damage but two of these were inadequately treated and the third died within two days of starting treatment. One patient with chronic fibrosis of six years' standing showed no improvement after four months' treatment with prednisone (Whitfield, 1959). Our present belief is that steroids should be given for three months to all patients whose lungs have not progressed to the stage of fibrosis. Even so it seems likely that sometimes the degree of lung damage is so great that death is inevitable whatever is done. The only other treatment that can be offered is rest during the acute phase, oxygen, sedatives to allay cough, and antibiotic cover to prevent secondary infection. Bergmann and Graham (1951) performed pneumonectomy in two patients with severe unilateral disease, and this procedure was considered in one of our patients who had bronchiectasis in a severely fibrotic lung. However, her psychological instability and the improvement that followed conservative measures made us decide not to proceed with surgical treatment.

PROPHYLAXIS Prevention of radiation lung damage is of course more important than its treatment. It may well be that some people are more sensitive to the harmful effects of radiation than others, but if this is so it is impossible to identify such subjects in advance of treatment. Age and arterial degenerative change do not appear to be relevant factors, but thin people do seem more liable to radiation lung damage than those of greater body weight (Desjardins, 1932; Whitfield et al., 1956). Rubin et al. (1958) and Stone et al. (1956) are of the opinion that the dominant influences in radiation lung damage are total dosage, rate of administration, and the percentage of the total lung volume irradiated, while Gish, Coates, DuSault, and Doub (1959) considered that the risk is reduced if treatment is protracted in time. Our own experience strongly supports these opinions. Evans (1960) has recently investigated a series of patients with carcinoma of the bronchus on these lines and found that if the maximum tumour dose did not exceed $5500 \mathrm{r}$, if the field was not more than $150 \mathrm{~cm} .^{2}$ and the treatment was spread over 60 days, only minimal radiation damage to the lung ensued. It is obvious therefore that wide-field therapy is only justifiable when it is the sole possible weapon of palliation or hope of cure, as for example in seminoma or chorion epithelioma lung secondaries. In addition dosage should not be unnecessarily high and treatment should be as protected as is reasonable.

In view of the possible therapeutic response to steroids in radiation lung damage we gave six patients, undergoing wide-field thoracic irradiation, prophylactic cortisone in a dose of 75-100 mg. daily during and for three months after radiotherapy. Of these, one died from radiation lung damage while still taking $50 \mathrm{mg}$. cortisone daily and another developed a small area of radiation pneumonia which cleared completely while taking a similar dose (Whitfield and Bond, 1959). Other workers (Chu et al., 1956) have had similarly disappointing results, but Friedenberg and Rubenfeld (1954) reported a series of patients in whom steroids appeared to afford some protection against radiation lung damage, and this certainly seemed to be so in respect of the rats studied by Moss, Haddy, and Sweany (1960). Animal experiments (Boys and Harris, 1943) have suggested that anticoagulant cover of thoracic radiotherapy may reduce the danger of radiation lung damage, and the work of Macht and Perlberg (1950) indicated that this was so in humans. We therefore gave phenindione to eight patients in whom wide-field thoracic irradiation was necessary, but of these three developed radiation pneumonia and one died from radiation damage to the heart.

\section{THE HEART}

The incidence and exact nature of radiation reactions in the heart are less clearly defined than is radiation lung damage. We have studied 27 patients clinically, radiologically, and electrocardiographically before, during, and after radiotherapy to the thorax, and of these 12 developed $T$ wave changes in the electrocardiogram. Two of the 12 died suddenly, apparently from cardiac arrest, and in one of these dyspnoea and gallop rhythm were evident for a few hours before death. In the other, necropsy showed no naked-eye or histological abnormality of the heart or coronary arteries and no cause for sudden death. Another of the 12 patients died from radiation damage to the lungs, and the heart showed no macroscopic or microscopic abnormality at necropsy despite the presence of electrocardiographic changes during life. The remaining nine had no cardiac symptoms and no objective cardiac abnormalities, and the electrocardiographic changes disappeared within a year or less. 
TABLE I

LESIONS FOR WHICH THORACIC RADIOTHERAPY WAS GIVEN

\begin{tabular}{ll}
$\begin{array}{l}\text { With Subsequent } \\
\text { New E.C.G. } \\
\text { Abnormality }\end{array}$ & $\begin{array}{l}\text { Without E.C.G. } \\
\text { Change }\end{array}$ \\
\hline 6 & 6 \\
3 & 4 \\
1 & 1 \\
2 & 2 \\
0 & 2
\end{tabular}

TABLE II

MEAN AGE IN RELATION TO ELECTROCARDIOGRAPHIC ABNORMALITY FOLLOWING RADIOTHERAPY TO THE THORAX

Patients showing subsequent new electrocardiographic abnormality

Patients showing no electrocardiographic change

Mean Age (yr.)

$50 \cdot 7$

$41 \cdot 1$

TABLE III

PREVIOUS CARDIOVASCULAR STATUS IN RELATION TO ELECTROCARDIOGRAPHIC ABNORMALITY FOLLOWING RADIOTHERAPY TO THORAX

\begin{tabular}{llc} 
& $\begin{array}{l}\text { With Subsequent } \\
\text { New E.C.G. } \\
\text { Abnormality }\end{array}$ & $\begin{array}{l}\text { Without } \\
\text { Subsequent } \\
\text { E.C.G. Change }\end{array}$ \\
\hline Normal & 9 & 10 \\
Hypertension & 2 & 2 \\
$\begin{array}{l}\text { Coronary artery disease } \\
\text { Rheumatic heart disease }\end{array}$ & 1 & 2 \\
$\quad$ and cardiac failure & 0 & 1
\end{tabular}

The primary disease of the 27 patients studied covered the usual range of conditions for which radiotherapy to the thorax is commonly given (Table I), and neither age (Table II) nor preexisting cardiac disease (Table III) seemed to be related to the subsequent development of electrocardiographic changes or to death. In one patient treated for carcinoma of the oesophagus, and in six patients given post-mastectomy radiotherapy for breast cancer through opposed axillary fields and a single parasternal field, $T$ wave inversion was only seen in leads $\mathrm{V}_{1}-\mathrm{V}_{3}$. In three given chest baths and in two treated through anterior and posterior $15 \times 15 \mathrm{~cm}$. fields for carcinoma of the bronchus, it occurred in most or all of the 12 leads.

The development of transient $T$ wave changes in the electrocardiogram after radiotherapy to the thorax has been reported by other writers (Gloriozov, 1949; Whitfield and Kunkler, 1957 ; Catterall, 1960 ; Catterall and Evans, 1960 ; Jones and Wedgwood, 1960 ; Vaeth, Feigenbaum, and Merrill, 1961) but their exact significance is uncertain. Some have suggested that they indicate direct radiation damage to the myocardium (Whitfield and Kunkler, 1957; Catterall and Evans, 1960) and, though the time of their appearance accords with this hypothesis, there is certainly no histopathological evidence to support it. On the contrary, much of the published work suggests that the myocardium is relatively insensitive to radiation. Certainly in animals very high dosage is necessary to produce recognizable myocardial damage (Davis, 1924; Hartman, Bolliger, Doub, and Smith, 1927; Warthin and Pohle, 1927, 1929 ; Werthemann, 1930 ; Leach and Sugiura, 1941, 1942) and the necropsy on the patient of Ross (1932) indicates that the same is true for humans. She reported a patient in whom a $2 \mathrm{mg}$. radium needle remained in the heart muscle for three years: such myocardial damage as was evident on examination of the heart after death was ischaemic in nature and resulted from narrowing of the lumina of smaller arterioles presumably due to radiation. The electrocardiographic changes seen in humans after radiotherapy to the thorax occur too soon to be explicable on this basis, and the histology of the myocardium in our fatal cases has shown no abnormality of the arteries or arterioles. Pearson (1958) reported two cases of myocardial infarction six months after $x$-ray treatment to the thorax, but this may well have been co-incidental as radiation does not usually produce changes in arteries as large as the main coronary arteries.

The work of Senderoff, Kahn, Peck, and Baronofsky (1960) and of Senderoff, Kaneko, Beck, and Baronofsky (1961) has shown that radiotherapy to the dog's thorax in comparable dosage to that used in humans does not produce any histologically identifiable myocardial injury. It tends to improve the blood supply to the myocardium, and any $T$ wave changes that may develop occur equally frequently in dogs that have not been irradiated. The $T$ wave changes that are seen in humans after radiotherapy are not however seen in normal people and must indicate some pathological change usually, if not always, mild, symptomless, transitory, and fully recoverable without treatment.

Leach (1943a), Blumenfeld and Thomas (1945), Hurst (1959), Jones and Wedgwood (1960), and Connolly (1962) have all reported constrictive pericarditis after radiotherapy to the thorax. Freid and Goldberg (1940) also described pericarditis in 8 of 18 patients with radiation lung damage, and Vaeth et al. (1961) noted pericarditis in 2 of 20 patients receiving $x$-ray treatment to the thorax. The $T$ wave changes in the electrocardiogram could therefore be due to pericarditis, but in our patients pericardial friction was never heard, and there was no clinical or radiological evidence of pericardial effusion or of the 
subsequent development of constrictive pericarditis.

Both of our patients who died suddenly showed increasing electrocardiographic abnormality during the days preceding death. In only one of these two was a necropsy obtained and the heart and coronary arteries were normal in the gross and microscopically, and no cause for sudden death was found. Although we are not sure that either death was related to radiation, we think that electrocardiographic changes after radiotherapy to the thorax may not always be unimportant or recoverable.

\section{THE AORTA}

We have not seen any damage to the aorta as a result of radiation but Thomas and Forbus (1959) reported a case in which, in addition to bilateral radiation pneumonia, there was localized necrosis of all layers of the aortic wall. Attempts at healing through proliferative connective tissue were evident, and fragments of thrombus which had formed at the site of injury had caused splenic and renal infarcts.

\section{THE OESOPHAGUS}

Previous writers have reported radiation strictures of the oesophagus (Seaman and Ackerman, 1957 ; Freid, 1948). We have seen seven patients with apparently non-malignant oesophageal strictures developing after radiotherapy to the thorax, larynx or thyroid. They appeared wholly fibrous on oesophagoscopy and biopsy showed no evidence of malignancy. We therefore made a diagnosis of radiation stricture but the subsequent course has shown that the stricture was in fact malignant in all seven patients. We think radiation stricture of the oesophagus must be very rare if it ever occurs. In patients who have sustained very gross radiation lung damage, oesophageal narrowing has not been evident radiologically though some distortion from extra-oesophageal fibrosis and hiatus hernia has sometimes been seen.

\section{SUMMARY}

Of all the thoracic tissues the lungs are the most vulnerable to radiation damage. The risk is increased when large areas of lung are irradiated, the total dosage is high, and the course of treatment is given quickly. Forty-nine cases after irradiation of the thorax for breast cancer, malignant lymphomas, lung secondaries, and oesophageal and bronchial cancer are reported. Seven of the 49 , all with severe bilateral damage, died from it. Steroids may be of some therapeutic value but their prophylactic use appears ineffective as does that of anticoagulants.

Thoracic irradiation may cause constrictive pericarditis or be followed by transitory $T$ wave changes in the electrocardiogram. The significance of the latter is uncertain. They are usually unassociated with cardiac symptoms or objective cardiac abnormality and disappear within a year or less. Twelve of 27 patients studied showed such changes, and sudden death occurred in two.

The most frequent manifestation of radiation damage to the bony structure of the thorax is fractured ribs. It usually follows post-mastectomy radiotherapy. Other less common bony lesions attributable to radiation are described.

Thoracic irradiation of females in childhood may result in mammary hypoplasia and absence of lactation.

Radiation stricture of the oesophagus was suspected in seven patients but the diagnosis was disproved in each instance: we think the condition must be rare.

We are greatly indebted to the consultant staff of the United Birmingham Hospitals for allowing us to study patients under their care, to Mr. T. F. Dee for reproduction of the figures, and to Miss J. Rutledge for help with the electrocardiograms.

\section{REFERENCES}

Baldwin, E. deF., Cournand, A., and Richards, D. W. (1949). Pulmonary insufficiency. II. A study of thirty-nine cases of pulmonary fibrosis. Medicine, Baltimore, $28,1$.

Baudisch, E. (1960). Beiträg zu den Strahlenschäden der Rippen und Schlüsselbeine bei Brustkrebs-Patienten. Strahlentherapie, 113, 312 .

Bergmann, M., and Graham, E. A. (1951). Pneumonectomy for severe irradiation damage of the lung. J. thorac. Surg., 22, 549.

Bluestein, S. G., and Roemer, J. (1953). The treatment of radiation pneumonitis with cortisone. J. med. Soc. N.J., 50, 106.

Blumenfeld, H., and Thomas, S. F. (1945). Chronic massive pericardial effusion following roentgen therapy for carcinoma of the breast; with a case report. Radiology, 44, 335.

Borgström, K. E., and Gynning, I. (1957). Roentgenographic changes in the lungs and vertebrae following intense rotation roentgen therapy of esophageal cancer. Acta radiol. (Stockh.), 47, 281.

Boys, F., and Harris, I. D. (1943). The effect of heparinization on experimental post-irradiation tissue changes in the lung. Amer. J. Roentgenol., $50,1$.

Braun, H., and Frik, W. (1954). Rippenschädigung nach Röntgenbestrahlung. Strahlentherapie, 94, 234.

Catterall, M. (1960). The effect of radiation upon the heart. Brit.J. Radiol., 33, 159.

and Evans, W. (1960). Myocardial injury from therapeutic irradiation. Brit. Heart J., $22,168$.

Chu, F. C. H., Nickson, J. J., and Uzel, A. R. (1956). The effect of ACTH and cortisone on radiation pneumonitis. Amer. J. Roentgenol., 75, 530.

Connolly, D. C. (1962). Personal communication

Cooper, G., Guerrant, J. L., Harden, A. G., and Teates, D. (1961). Some consequences of pulmonary irradiation. Amer. J. Roentgenol., 85,865 .

Cosgriff, S. W., and Kligerman, M. M. (1951). Use of ACTH and cortisone in the treatment of post-irradiation pulmonary reaction. Radiologv, 57, 536 .

Davis, K. S. (1924). Intrathoracic changes following X-ray treatment: a clinical and experimental study. Ibid., 3, 301.

Desjardins, A. U. (1932). Action of Roentgen rays and radium on the heart and lungs. Amer. J. Roentgenol., 28, 699. 
Douglas, A. C. (1959). Treatment of radiation pneumonitis with prednisolone. Brit. J. Dis. Chest, 53, 346.

Eggs, F. (1941). Osteoradionekrose der Rippen nach Röntgenbestrahlung des Mammakarzinoms. Strahlentherapie, 70, 315.

Evans, J. C. (1960). Time-dose relationship of radiation; fibrosis of lung. Radiology, 74, 104.

Fike, R. H. (1932). The occurrence of Roentgen pleuropneumonitis in treatment of breast cancer. Amer. J. Roentgenol., 27, 509.

Freid, J. R. (1948). Roentgen treatment of cancer of the esophagus. Ibid., 59, 551 .

- and Goldberg, H. (1940). Post-irradiation changes in the lungs and thorax. Ibid., 43, 877.

Friedenberg, R. M., and Rubenfeld, S. (1954). The role of cortisone in preventing pulmonary fibrosis following irradiation. Ibid., 72, 271.

Gish, J. R., Coates, E. O., DuSault, L. A., and Doub, H. P. (1959). Pulmonary radiation reaction: A vital capacity and time-dose study. Radiology, 73, 679 .

Gloriozov, B. N. (1949). Effect of Roentgenotherapy on heart electrocardiogram in patients with esophageal cancer during Roentgenotherapy according to Dillon method. Klin. Med. (Mosk.) (in Russian), No. 12, 27, p. 60.

Gros, C. M., and Keiling, R. (1958). Aplasie d'un sein après roentgenthérapie profonde pour un sarcome médiastinal. J. Radiol. Electrol. 39, 636 .

Hartman, F. W., Bolliger, A., Doub, H. P., and Smith, F. J. (1927). Heart lesions produced by the deep x-ray: an experimental and clinical study. Bull. Johns Hopk. Hosp., 41, 36.

Hurst, D. W. (1959). Radiation fibrosis of pericardium, with cardiac tamponade: case report with post-mortem studies and review of literature. Canad med. Ass. J.,81, 377.

Jones, A., and Wedgwood, J. (1960). Effects of radiations on the heart. Brit. J. Radiol., 33, 138.

Kolár, J., and Vrabec, R. (1957). Ủber Knochenschäden beim Röntgengeschwür. Strahlentherapie, 102, 112.

and Bek, V. (1957). Entwicklungsstörungen der weiblichen

intern. Med., 72,715.
(1943b). Abnormal pulmonary physiology as a result of chronic irradiation pleuropulmonitis. Amer. J. Roentgenol., 50, 772 .

irradiation pleuropulmonitis. Amer. J. Roentgenol., 50, 772 .
Farrow, J. H., Foote, F. W., and Wawro, N. W. (1942). Fibrosis of the lung following roentgen irradiation for cancer of the breast. Ibid., 47, 740 .

- and Sugiura, K. (1941). The effect of high voltage roentgen rays on the heart of adult rats. Ibid., 45, 414.

(1942). Late effect of high voltage roentgen rays on heart of adult rats. Ibid., 48, 81 .

Lichtenstein, H. (1960). X-ray diagnosis of radiation injuries of the lung. Dis. Chest $, 38,294$.

Lougheed, M. N., and Maguire, G. H. (1960). Irradiation pneumonitis in the treatment of carcinoma of the breast. J. Canad. Ass. Radiol., 11, 1 .

Macht, S. H., and Perlberg, H. (1950). Use of anticoagulant (dicumarol) in preventing post-irradiation tissue changes in the human lung. Amer. J. Roentgenol., 63, 335.
Moss, W. T., Haddy, F. J., and Sweany, S. K. (1960). Some factors altering the severity of acute radiation pneumonitis: variation with cortisone, heparin, and antibiotics. Radiology, 75, 50.

Pearson, H. E. S. (1958). Incidental dangers of X-ray therapy. Lancet, $1,222$.

Rall, J. E., Alpers, J. B., Lewallen, C. G., Sonenberg, M., Berman, M., and Rawson, R. W. (1957). Radiation pneumonitis and fibrosis: A complication of radioiodine treatment of pulmonary metastases from cancer of the thyroid. J. clin. Endocr., 17, 1263.

Rodman, T., Karr, S., and Close, H. P. (1960). Radiation reaction in the lung. Report of a fatal case with carcinoma of the lung, with studies of pulmonary function before and during prednisone therapy. New Engl. J. Med. $262,431$.

Ross, J. M. (1932). A case illustrating the effects of prolonged action of radium. J. Path. Bact., 35, 899.

Rübe, W. (1954). Hypoplasia mammae unilateralis durch Radiumbestrahlung eines Haemangioms. Strahlentherapie, 94, 561.

Rubin, P., Andrews, J. R., Paton, R., and Flick, A. (1958). Response of radiation pneumonitis to adrenocorticoids. Amer. J. Roentgenol., 79, 453.

Seaman, W. B., and Ackerman, L. V. (1957). The effect of radiation on the esophagus. Radiology, 68, 534

Senderoff, E., Kahn, M., Peck, H., and Baronofsky, I. D. (1960). The effect of cardiac irradiation upon the electrocardiogram of the normal canine heart. Amer. J. Roentgenol.. 83, 1078.

- Kaneko, M., Beck, A. R., and Baronofsky, I. D. (1961). The effects of cardiac irradiation upon the normal canine heart. Ibid., 86, 740 .

Stone, D. J., Schwartz, M. J., and Green, R. A. (1956). Fatal pulmonary insufficiency due to radiation effect upon the lung. Amer. J. Med., 21, 211 .

Thomas, E., and Forbus, W. D. (1959). Irradiation injury to the aorta and the lung. Arch. Path., 67, 256.

Vaeth, J. M., Feigenbaum, L. Z., and Merrill, M. D. (1961). Effects of intensive radiation on the human heart. Radiology, 76, 755 .

Warthin, A. S., and Pohle, E. A. (1927). The effect of roentgen rays on the heart. 1. The microscopic changes in the heart muscle of rats and rabbits following a single exposure. J. Amer. med. Ass. $89,1825$.

(1929). The effect of roentgen rays on the heart. II. The microscopic changes in the heart muscle of rats and of rabbits following a series of exposures. Arch. intern. Med., 43, 15.

Werthemann, A. (1930). Experimentelle Röntgenschädigungen des Herzmuskels. Strahlentherapie, 38, 702.

Whitfield, A. G. W. (1959). Steroid therapy in pulmonary fibroses. Brit. J. Dis. Chest., 53, 28.

and Bond, W. H. (1959). The prevention of radiation lung damage. J. Fac. Radiol. (Lond.), 10, 181. damage. J. Fac. Radiol. (Lond.), 10, 181.
and Arnott, W. M. (1954). Pulmonary irradiation effects and their treatment with cortisone and ACTH. Ibid., 6, 12. Med., 25, 67.

. Brit. Heart J., 19, 53 .

- Lannigan, R., and Bond. W. H. (1954). Fatal post-radiation pneumonitis. Lancet, $2,117$. 